\title{
Inappropriate prescribing to the oldest old patients admitted to hospital: prevalence, most frequently used medicines, and associated factors
}

Antonio San-José ${ }^{1,9^{*}}$, Antonia Agustî ${ }^{2}$, Xavier Vidal ${ }^{2}$, Francesc Formiga ${ }^{3,9}$, Mercedes Gómez-Hernández ${ }^{4,9}$, Juana García ${ }^{5,9}$, Alfonso López-Soto 6,9, Nieves Ramírez-Duque ${ }^{7,9}$, Olga H Torres ${ }^{8,9}$, José Barbé ${ }^{1,9}$ and on behalf of Potentially Inappropriate Prescription in Older Patients in Spain (PIPOPS) Investigators' project

\begin{abstract}
Background: Scientific evidence on treatments of chronic diseases in patients 85 years old or older is very limited, as is available information on inappropriate prescription (IP) and its associated factors. The study aimed to describe medicine prescription, potentially inappropriate medicines (PIM) and potentially prescribing omissions (PPO) and their associated factors on this population.

Methods: In the context of an observational, prospective and multicentric study carried out in elderly patients admitted to seven Spanish hospitals for a year, a sub-analysis of those aged 85 years and over was performed. To assess PIMs, the Beers and STOPP criteria were used, and to assess PPOs, the START and the ACOVE-3 criteria were used. To assess factors associated with IP, a multivariate logistic regression analysis was performed. Patients were selected randomly every week on consecutive days from the hospitalization lists.

Results: A total of 336 patients were included in the sub-analysis with a median (Q1-Q3) age of 88 (86-90) years. The median medicines taken during the month prior to admission was 10 (7-13). Forty-seven point two per cent of patients had at least one Beers-listed PIM, 63.3\% at least one STOPP-listed PIM, 53.6\% at least one START-listed PPO, and $59.4 \%$ at least one ACOVE-3-listed PPO. Use of benzodiazepines in patients who are prone to falls (18.3\%) and omission of calcium and vitamin D supplements in patients with osteoporosis (13.3\%) were the most common PIM and PPO, respectively. The main factor associated with the Beers-listed and the STOPP-listed PIM was consumption of 10 or more medicines $(\mathrm{OR}=5.7,95 \% \mathrm{Cl} 1.8-17.9$ and $\mathrm{OR}=13.4,95 \% \mathrm{Cl}$ 4.0-44.0, respectively). The main factors associated with the START-listed PPO was a non-community dwelling origin (OR $2.3,95 \% \mathrm{Cl} 1.0-5.0)$, and multimorbidity (OR1.8, 95\% Cl 1.0-3.1).

Conclusions: Prescribed medicines and PIM and PPO prevalence were high among patients 85 years and over. Benzodiazepine use in those who are prone to falls and omission of calcium and vitamin D in those with osteoporosis were the most frequent PIM and PPO, respectively. Factors associated with PIM and PPO differed with polypharmacy being the most important factor associated with PIM.
\end{abstract}

Keywords: Oldest old, Polypharmacy, Potentially inappropriate medicines, Potentially prescribing omissions, Benzodiazepines, Calcium and vitamin D supplements

\footnotetext{
* Correspondence: asanjose@vhebron.net

'Internal Medicine Service, Hospital Universitari Vall d'Hebron, Universitat

Autònoma de Barcelona, Àrea General 3a planta, Passeig Vall d'Hebron

119-129, 08035 Barcelona, Spain

${ }^{9}$ Multimorbidity and elderly patients group of the Spanish Society of Internal

Medicine, Barcelona, Spain

Full list of author information is available at the end of the article
}

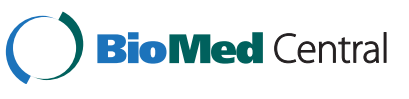

(C) 2015 San-Jose et al.; licensee BioMed Central. This is an Open Access article distributed under the terms of the Creative Commons Attribution License (http://creativecommons.org/licenses/by/4.0), which permits unrestricted use, distribution, and reproduction in any medium, provided the original work is properly credited. The Creative Commons Public Domain Dedication waiver (http://creativecommons.org/publicdomain/zero/1.0/) applies to the data made available in this article unless otherwise stated. 


\section{Background}

Appropriate prescribing of medicines in the elderly and especially in the very elderly is a major clinical and economic issue. The group of the oldest old people ( 85 years and over) is increasing and will increase even more in western countries in the coming years. Therefore, health care and appropriate use of medicines in this group is one of the major challenges facing health care systems in these countries [1]. In this age group there is often significant multimorbidity [2,3], with limited scientific evidence available on the treatment of various chronic diseases in this aforementioned group [4]. This is due to the lack of high quality evidence on the benefits and safety of treatments for major chronic diseases in this group $[5,6]$, and their exclusion from clinical trials $[7,8]$. This means that most clinical practice guidelines for major chronic diseases do not include clear recommendations for the very elderly. Therefore, to treat patients in clinical practice, an individualized approach that incorporates a comprehensive geriatric assessment is recommended [4,9-11].

Recently, medicines consumption in the oldest old has been a matter of interest [12-14]. Although to our knowledge, no studies focusing on the use and the usefulness in people 85 years old and over of the main criteria for potentially inappropriate prescription medicines, have been published.

In the context of a multicentric study focused on inappropriate prescribing of medicines in the elderly (patients 75 years old and over) in the month prior to hospital admission [6], a sub-analysis of those aged 85 years old or over was performed. The goals of this sub-analysis were: to describe the use of medicines in this very elderly group of patients, to assess inappropriate use of medicines and the associated factors, and finally to compare the results with those obtained in the group of 75 to 84 year old patients. The initial hypothesis was that, despite a shorter life expectancy and the lack of solid scientific evidence regarding the treatment of most chronic conditions in the very elderly people, polypharmacy and the percentage of potentially inappropriate use of medicines remain as high as those described for the group of 75 to 84 year old.

\section{Methods}

An observational, prospective, multicentric study on a cohort of patients hospitalised in the Internal Medicine Services of seven Spanish hospitals was carried out for a year (from April 2011 to March 2012). The study methodology has been described in previous papers $[15,16]$ and this is a study focusing on the oldest old patients (85 years or more).

In brief, patients 75 years or older admitted with an acute illness or an exacerbation of a chronic condition who signed the informed consent form, were included. Signed informed consent was obtained from patients or caregivers in case of cognitive impairment (dementia or delirium). Hospital admission was through either the emergency department or directly from primary care. Patients with a scheduled or a short-duration (less than 24 hours) admission, those seen as an outpatient by the researcher, and those where no access was available to primary care medical information were excluded from the study. Each hospital included 2 patients per week admitted with the inclusion criteria. Patients were selected randomly every week on consecutive days from the hospitalization lists. By design, half of the included patients were 85 years or older. Beers criteria 2003 [17], STOPP and START criteria $[18,19]$ and ACOVE-3 underprescribing indicators for chronic conditions [16] were applied to each dataset on admission. In the study, Beers-listed Potentially Inappropriate Medicines (PIM), when at least one of the Beers criteria was prescribed, STOPP-listed PIM, when at least one STOPP criteria was prescribed, STARTlisted Potentially Prescribing Omissions (PPO), when at least one START criteria was omitted, and ACOVE-3-listed PPO, when at least one ACOVE- 3 criteria was omitted. The study was approved by the Ethics Committee of Clinical Investigation in each participating hospital (Hospital Universitari Vall d'Hebron, Barcelona; Hospital Clínic, Barcelona; Hospital Universitari de Bellvitge, Hospitalet de Llobregat; Hospital Santa Creu i Sant Pau, Barcelona; Hospital Universitari Virgen del Rocio, Sevilla; Hospital San Juan de Dios del Aljarafe, Sevilla; Hospital General Juan Ramón Jiménez, Huelva).

Information on a patient's characteristics and the prescribing medicines was obtained from the hospital and the primary care electronic medical records and from interviews with the patients and/or relatives, using a structured questionnaire (see online Additional file 1) [15].

Since the number of eligible patients was different for the participating centres, analyses were weighted by frequency of the eligible population in each hospital. Descriptive results for continuous and count variables are shown as median, first (Q1), and third (Q3) quartiles. Comparisons for continuous and count variables were done using regression analyses, and for categorical ones using Rao-Scott Chi-square tests. To examine the association between inappropriate prescribing and potential risk factors, a multivariate logistic regression analysis was performed where an inappropriate prescribing indicator was the dependent variable and sociodemographic variables, multimorbidity, number of prescription medicines in the preceding month before hospitalization and the other indicators of inappropriate prescription (STOPPlisted PIM, Beers-listed PIM, ACOVE-3-listed PPO and START-listed PPO) were the independent variables. The adjusted Odds ratio (OR) with its $95 \%$ confidence intervals 
(CI) was calculated. Statistical analysis was performed using the procedures for complex surveys of the SAS 9.2 program (SAS Institute Inc., Cary, NC, USA).

\section{Results}

Three hundred thirty-six out of a total of 672 patients were included in the sub-analysis and the median (Q1Q3) age was 88 (86-90). The main clinical characteristics of the group of the oldest old are shown in Table 1 as well as the differences between patients aged 75 to 84 years. The oldest old patients, significantly, lived more often with their families than with their partners or alone ( $\mathrm{p}<0.001)$, had a worse functional status $(\mathrm{p}<0.0001)$ and a poorer cognitive baseline function ( $\mathrm{p}<0.001)$. They were more often discharged to nursing home facilities and less often to their homes ( $\mathrm{p}<0.001)$.

Median (Q1-Q3) medicines taken during the month prior to admission was 10 (7-13). The most frequently prescribed medicine was omeprazole and the main differences compared to the group of patients aged 75 to 84 were a higher prescription of acethylsalicylic acid (38.1\% for those 85 years and over versus $29.7 \%$ in the group from 75 to 84 years), lorazepam (21.5\% versus $15.3 \%)$, amlodipine (18.8\% versus $13.2 \%$ ) and paraceta$\mathrm{mol}(51.5 \%$ vs. $45.2 \%)$ and a lower prescription of acenocoumarol (16.2\% versus $26.0 \%)$ and simvastatin $(16.4 \%$ versus $21.7 \%$ ) (Table 2 ).

Forty-seven point two percent of patients aged 85 and older had at least one Beers-listed PIM, 63.3\% at least one STOPP-listed PIM, 53.6\% at least one START-listed PPO, and $59.4 \%$ at least one ACOVE-3-listed PPO, which was not significantly different to the group aged 75 to 84 (Table 3).

In the oldest old patients, the most frequently found PIMs according to the Beers' criteria was the use of short to intermediate acting benzodiazepines in patients with previous falls or syncope (10.7\%) and the use of long-acting benzodiazepines independent of diagnoses or conditions (10.5\%). The most commonly encountered STOPP criteria was the use of benzodiazepines in patients who are prone to falls $(18.3 \%)$ and the use of longterm long-acting benzodiazepines (9.5\%). Among the START criteria the most frequently identified PPO were ACE inhibitors in patients with heart failure $(12.8 \%)$ and oral anticoagulation in the presence of chronic atrial fibrillation (12.8\%). The most commonly identified PPO using the ACOVE criteria were calcium and vitamin D supplements in patients with osteoporosis (13.3\%) and ACE inhibitors or angiotensin-receptor blockers in patients with hypertension and comorbid vascular diseases (10.8\%).

With regard to PIM, the main difference according to the STOPP criteria was a higher prescription of benzodiazepines for patients with a history of falls in the group of the oldest old (18.4\% versus $13.1 \%$ in those aged 75 to $84, p=0.090$ ), although the difference was not statistically significant. Regarding PPO, the main differences were a lower prescription of vitamin D and calcium supplements in patients with known osteoporosis in the group of the oldest old according to both the START (5.6\% versus $11.3 \%, \mathrm{p}=0.013)$ and the ACOVE- 3 criteria $(5.7 \%$ versus $13.3 \%, p=0.002$ ), and a lower prescription of $\beta$-blocking agents in patients with arterial hypertension and ischemic heart disease according to the ACOVE- 3 criteria (4.3\% versus $10.6 \%, \mathrm{p}=0.002$ ) (Table 4 ).

The results of the multivariate regression analysis are shown in Table 5. Only the statistically significant risk factors are presented. In the oldest old, a prescription of ten or more medicines was the most important independent factor associated with an increased risk of at least one Beers-listed PIM (OR 5.7, 95\% CI 1.8-17.9). A prescription of ten or more medicines (OR 13.4, 95\% CI 4.0-44.0) and a severe dependence in basic activities of daily living (OR 5.0, 1.1-22.1) were the independent factors associated with an increased risk of at least one STOPP-listed PIM. Instead, multimorbidity was associated with a reduced risk of at least one STOPP-listed PIM (OR $0.5,0.2-0.9$ ). In comparison to patients aged 75 to 84 , female gender was not associated with an increased risk of PIM in the oldest old. In the oldest old, the independent factors associated with an increased risk of at least one START-listed PPO were a non-community dwelling (OR 2.3, 95\% CI 1.0-5.0), and multimorbidity (OR 1.8, 1.0-3.1). The only factor associated with an increased risk of at least one ACOVE-3-listed PPO was the presence of at least one STOPP-listed PIM (OR 2.4, 1.4-4.3). These factors were also associated with PPO in the group of patients aged 75 to 84 with the exception of a non-community dwelling.

\section{Discussion}

This study shows that in patients 85 years and older, polypharmacy and prevalence of inappropriate prescribing, both for PIM and PPO, were as high as those in the younger elderly. The assessed population was very elderly and with significant frailty, multimorbidity and dependence in ADL as has already been described in other studies $[3,13,20]$.

In our study, the most frequently prescribed medicine for patients aged 85 and over was omeprazole, but without a significant difference in comparison with those aged 75 to 84. Among the most frequently prescribed medicines, the consumption of paracetamol, aspirin, amlodipine and lorazepam was higher and that of acenocoumarol and simvastatin lower in the very elderly in comparison to those aged 75 to 84 . A lower use of anticoagulation therapy in the oldest old population with anticoagulation criteria is one of the most frequent causes of underprescribing in the elderly $[15,21]$. However, in our study no statistically significant 
Table 1 Baseline characteristics of patients (weighted percentages)

Baseline characteristics 85 and more years

336 patients

Age (median [Q1-Q3])

Gender female (\%)

Admission reason (\%)

- Acute disease

- Exacerbation of chronic disease

Emergency room origin (\%)

Dwelling (\%)

- Community

- Nursing Home

Living with (\%)

- Partner

- Family

- Single

- Others

GP visits during previous month (\%)

- None

- One or two

- Three or more

Admissions during the previous month (\%)

- None

- One

- Two or more

Barthel Index (median [Q1-Q3])

- Basal

- On admission

- On discharge

GDS basal (\%)

- $1-2$

- 3-5

- 6-7

Positive CAM on admission (\%)

Failures in Pfeiffer test (median [Q1-Q3])

Charlson Index (median [Q1-Q3])

Multimorbidity (\%)

Number of medicines (median [Q1-Q3])

Number of medicines (\%)

- $0-4$

- 5-9

- 10 and more

88 (86-90)

60.8

54.4

45.6

94.6

82

18

\section{3}

51.4

9.6

22.7

48.1

41.7

10.2

85.2

14.2

0.6

60 (35-80)

30 (5-55)

45 (15-65)

44.1

41.5

14.4

20.38

3 (2-5)

$2(1-4)$

67

10 (7-13)

9.4

37.5

53.1
75-84 years

336 patients

80 (77-82)

53.6

$<0.001$

0.086

0.308

50.1

49.9

92.4

0.285

0.004

91.5

8.5

$<0.001$

32.4

38.2

17.6

11.8

35.9

51.8

12.3

0.077

84.7

12.5

2.8

80 (55-95)

$<0.001$

55 (20-70)

$<0.001$

65 (35-80)

$<0.001$

$<0.001$

65.1

25.0

9.9

11.66

0.004

2 (0-4)

$<0.001$

$3(1-4)$

0.034

59.3

0.060

10 (7-14)

0.185

0.400
6.6

36.2

57.2 
Table 1 Baseline characteristics of patients (weighted percentages) (Continued)

\begin{tabular}{lll}
\hline Discharged to (\%) & & $<0.4$ \\
- Home & 66 & 12.4 \\
- Nursing Home & 23.7 & 1.2 \\
- Another Hospital & 0.7 & 6
\end{tabular}

GP: General Practitioner; GDS: Global Deterioration Scale; CAM: Confusion Assessment Method.

differences were found between both age groups using the START and ACOVE-3 criteria.

It is noteworthy that for patients aged 85 and over, compared to the younger group, the main cause of PIM, both for the Beers and the STOPP criteria, was a higher use of benzodiazepines, especially in people with a history of falls detected using the STOPP criteria. The relationship between benzodiazepine use and an increased risk of falls is well known [22], as is the use of benzodiazepines being the leading cause of PIM $[9,20]$, although most of these studies did not focus on the very elderly. Recently, some authors have looked at reducing prescribing benzodiazepines [23], and in some studies, benzodiazepines' cessation has been associated with a reduction in falls [24]. However, these studies did not focus on the very elderly.

Regarding PPO, the main differences in comparison to patients aged 75 to 84 , were a greater omission of calcium and vitamin D supplements in the oldest old with osteoporosis according to the START and the ACOVE- 3 criteria, and a greater omission of $\beta$-blockers in the oldest old with arterial hypertension and ischemic heart disease using the ACOVE-3 criteria. A high prevalence of vitamin $\mathrm{D}$ deficiency in patients aged 85 years and over [25], and

Table 2 The most frequently prescribed medicines according to age groups

\begin{tabular}{lllll}
\hline $\mathbf{8 5}$ years old and over & & & 75 to 84 years old & \\
\cline { 1 - 2 } \cline { 5 - 6 } Medicine & $\%$ & & Medicine & \% \\
\hline omeprazole & 61.4 & & omeprazole & 61.2 \\
paracetamol & 51.5 & & paracetamol & 45.2 \\
furosemide & 47.0 & & furosemide & 43.7 \\
acethylsalicylic acid & 38.1 & & acethylsalicylic acid & 29.7 \\
lorazepam & 21.5 & & acenocoumarol & 26.0 \\
enalapril & 20.8 & & enalapril & 21.9 \\
amlodipine* & 18.8 & & simvastatin & 21.7 \\
metformin & 18.6 & & metformin & 21.7 \\
nitroglycerin nitrate & 17.4 & & ipratropium bromide & 19.1 \\
simvastatin & 16.4 & & hydrochlorothiazide & 16.9 \\
ipratropium bromide & 16.3 & & metamizole & 16.8 \\
acenocoumarol & 16.2 & & lorazepam & 15.3 \\
hydrochlorothiazide & 15.8 & nitroglycerin nitrate & 14.8 \\
\hline
\end{tabular}

*Amlodipine $13.26 \%$ in those aged 75 to 84 . the association between hypovitaminosis $\mathrm{D}$ and various health problems in the elderly have been described [26]. Moreover, omission of calcium and vitamin D supplements in the elderly with osteoporosis has been the leading cause of PPO in different studies [21,27]. This is relevant, taking into account the benefit of calcium and vitamin D supplements in preventing bone loss and fractures in elderly people with osteoporosis [28,29], although once again, these studies were not performed on the very elderly. The higher omission of $\beta$-blockers in the oldest old with hypertension and ischemic heart disease may be due to more frequent use of other antihypertensives in this frail group.

The main factor associated with PIM in both age groups was polypharmacy, especially when 10 or more medicines were taken. The strong association between polypharmacy and PIMs [21,30] and also the higher prevalence of PIM when STOPP criteria was used in comparison to the Beers criteria have already been reported on in other studies [9,21]. The association between a severe dependency in ADL and PIM found in our study can be explained, at least in part, by the high prevalence of dementia in this population.

Regarding PPO in patients aged 85 years or older, the relevant findings in our study were the higher ACOVE-3 PPO criteria prevalence, and the association between a nursing home origin and multimorbidity with the START criteria. That is, patients from a nursing home and those with multimorbidity had a higher risk of underprescription. The lack of association between polypharmacy and PPO is well known [30], as is the scarce scientific evidence available regarding risk factors associated with underprescribing. The association with multimorbidity has also been described in other studies [21], and other described factors have been advanced age $[19,21]$, and female gender [19]. The high proportion of

Table 3 Prevalence of PIM and PPO according to the criteria

\begin{tabular}{llll}
\hline Criteria & $\mathbf{8 5}$ years and over $\%$ & $\mathbf{7 5}$ to $\mathbf{8 4}$ years old $\%$ & $\mathbf{P}$ \\
\hline Beers & 47.28 & 53.76 & $P=0.126$ \\
STOPP & 63.36 & 60.47 & $P=0.482$ \\
START & 53.68 & 49.65 & $P=0.342$ \\
ACOVE3 & 59.40 & 54.91 & $P=0.289$ \\
\hline
\end{tabular}


Table 4 Main potentially inappropriate medicines (PIM) and potentially prescribing omissions (PPO) in patients aged 85 years and over compared with those aged 75 to 84 years

\begin{tabular}{|c|c|c|c|c|}
\hline Disease or condition & Drug & $\begin{array}{l}85 \text { years } \\
\text { and over \% }\end{array}$ & $\begin{array}{l}75-84 \\
\text { years \% }\end{array}$ & $\mathrm{p}$ \\
\hline \multicolumn{5}{|l|}{ Beers list PIM } \\
\hline Syncope or falls & Short- to intermediate-acting benzodiazepine and tricyclic antidepressants & 10.7 & 9.8 & 0.712 \\
\hline Independent diagnosis & Long-acting benzodiazepines & 10.5 & 12.7 & 0.268 \\
\hline \multicolumn{5}{|l|}{ STOPP list PIM } \\
\hline $\begin{array}{l}\text { Drugs that adversely affect } \\
\text { those prone to falls }\end{array}$ & Benzodiazepines & 18.4 & 13.2 & 0.090 \\
\hline $\begin{array}{l}\text { Central nervous system } \\
\text { and psychotropic drugs }\end{array}$ & Long-term (i.e. >1 month), long-acting benzodiazepines & 9.5 & 11.7 & 0.687 \\
\hline Cardiovascular system & Aspirin at dose $>150 \mathrm{mg}$ day & 8.6 & 4.9 & 0.106 \\
\hline Cardiovascular system & $\begin{array}{l}\text { Aspirin with no history of coronary, cerebral or peripheral arterial symptoms or } \\
\text { occlusive arterial event }\end{array}$ & 7.8 & 7.5 & 0.909 \\
\hline \multicolumn{5}{|l|}{ START list PPO } \\
\hline Cardiovascular system & ACE inhibitor with chronic heart failure & 12.8 & 13.5 & 0.750 \\
\hline Cardiovascular system & Warfarin in the presence of chronic atrial fibrillation & 12.8 & 10.3 & 0.343 \\
\hline Musculoskeletal system & Calcium and vitamin D supplement in patients with known osteoporosis & 11.3 & 5.6 & 0.013 \\
\hline Endocrine system & $\begin{array}{l}\text { Antiplatelet therapy in diabetes mellitus if one or more coexisting major } \\
\text { cardiovascular risk factor present }\end{array}$ & 8.8 & 10.3 & 0.530 \\
\hline \multicolumn{5}{|l|}{ ACOVE 3 list PPO } \\
\hline Osteoporosis & $\begin{array}{l}\text { IF a VE has osteoporosis, THEN he or she should be prescribed calcium and } \\
\text { vitamin D supplements }\end{array}$ & 13.3 & 5.7 & 0.002 \\
\hline Hypertension & $\begin{array}{l}\text { IF a VE with HTN has a history of HF, left ventricular hypertrophy, IHD, chronic } \\
\text { kidney disease, or cardiovascular accident, THEN he or she should be treated with } \\
\text { an ACE inhibitor or ARB }\end{array}$ & 12.6 & 9.9 & 0.289 \\
\hline Stroke and atrial fibrillation & $\begin{array}{l}\text { IF a VE has chronic atrial fibrillation and is at medium to high risk for stroke, THEN } \\
\text { anticoagulation should be offered. }\end{array}$ & 10.7 & 8.1 & 0.242 \\
\hline Hypertension & $\begin{array}{l}\text { IF a VE with HTN has IHD, THEN treatment with a beta-blocker should be } \\
\text { recommended or documentation of why it should not be provided. }\end{array}$ & 10.6 & 4.3 & 0.002 \\
\hline Osteoporosis & $\begin{array}{l}\text { IF a female VE has osteoporosis, THEN she should be treated with } \\
\text { bisphosphonates, raloxifene, calcitonin, hormone replacement therapy, or } \\
\text { teriparatide }\end{array}$ & 10.5 & 7.4 & 0.163 \\
\hline
\end{tabular}

PIM and PPO in the elderly institutionalized in nursing homes is known about [31]. Moreover, the implementation of the STOPP/START criteria has been associated with a reduction in the number of drugs and falls in this population [32]. The association between underprescribing and a nursing home origin found in our study is curious. In contrast, a low START-listed PPO prevalence in patients with dementia has been described [21]. The authors of this study argued that patients with dementia are probably more often institutionalized in nursing home facilities with more organized pharmaceutical care. More studies are needed to clarify the association between underprescribing and a nursing home origin.

Something new that we have found is a link between PIM and PPO in a very elderly population with polypharmacy. This may be explained because a large percentage of patients in our study had PIM and PPO at the same time [15]. However, this is a surprising finding because risk factors associated with PIM and PPO did not match in several other studies $[15,18,19,21]$. More information on risk factors simultaneously associated with PIM and PPO in very elderly patients with polypharmacy is needed. Moreover, the association between multimorbidity and PPO has been previously reported on in the elderly, but the inverse association with PIM is more striking. It seems that in the very elderly with multimorbidity, physicians avoid medicines included in the PIM criteria with a low level of scientific evidence on their efficacy and/or with better alternatives.

In the elderly patients with multimorbidity, and especially in the oldest old, the usefulness of underprescribing tools is controversial. A high prevalence of medicine omission is often described when they are systematically used in these patients [19,21], although, as discussed above, the available evidence on treatments of chronic diseases in these patients are low or insufficient [4]. 
Table 5 Results of the multivariate regression analysis

\begin{tabular}{|c|c|c|c|c|c|}
\hline \multicolumn{3}{|l|}{85 years old and over } & \multicolumn{3}{|l|}{75 to 84 years old } \\
\hline Associated factor & OR $(95 \% \mathrm{Cl})$ & $\mathrm{p}$ & Associated factor & OR $(95 \% \mathrm{Cl})$ & $\mathbf{p}$ \\
\hline Beers & & & Beers & & \\
\hline Number of medicines & & & Number of medicines & & \\
\hline \multirow[t]{4}{*}{ - 10 or more } & $5.7(1.8-17.9)$ & 0.003 & - $5-9$ & $6.3(1.1-34.4)$ & 0.035 \\
\hline & & & - 10 or more & $11.0(2.0-59.7)$ & 0.006 \\
\hline & & & Female gender & $1.9(1.1-3.1)$ & 0.014 \\
\hline & & & START-listed PPO & $1.8(1.0-2.9)$ & 0.027 \\
\hline STOPP & & & STOPP & & \\
\hline Number of medicies & & & Number of medicines & & \\
\hline - 5 - 9 & $5.7(1.8-17.8)$ & 0.003 & - 10 or more & $5.1(1.5-16.8)$ & 0.007 \\
\hline - 10 or more & $13.4(4.0-44.0)$ & $<0.001$ & ACOVE-3-listed PPO & $2.2(1.2-3.6)$ & 0.004 \\
\hline \multicolumn{6}{|l|}{ Severe dependence in } \\
\hline ADL & $5.0(1.1-22.1)$ & 0.031 & & & \\
\hline Multimorbidity & $0.5(0.2-0.9)$ & 0.045 & & & \\
\hline START & & & START & & \\
\hline Non-community dwelling & $2.3(1.0-5.0)$ & 0.030 & Multimorbidity & $1.9(1.0-3.2)$ & 0.027 \\
\hline Multimorbidity & $1.8(1.0-3.1)$ & 0.040 & & & \\
\hline ACOVE-3 & & & ACOVE-3 & & \\
\hline STOPP-listed PIM & $2.5(1.4-4.3)$ & 0.001 & STOPP-listed PIM & $2.2(1.2-3.8)$ & 0.004 \\
\hline
\end{tabular}

Only the statistically significant risk factors associated to PIM and PPO tools are presented.

Our study has several strengths. Firstly, it was carried out on a large group of very elderly people and is a topic that has infrequently been investigated. Secondly, a rigorous methodology in both the geriatric and the pharmacological assessment of patients was applied, and thirdly it was a multicentric study involving seven hospitals lasting a year.

This study also has some limitations. Firstly, the Beers' criteria version 2003 was used, and currently there is a new one [33] which only appeared once the study was initiated. A new version of the STOPP/START criteria has also been published very recently, although the indicators identified in our study as the most prevalent in the oldest old remain unchanged in the new version [34]. Secondly, only patients admitted to medical units in hospitals were included and they are not representative of the very elderly community dwelling patients. Finally, the consequences of inappropriate prescribing were not analysed.

\section{Conclusions}

In our study, a high prevalence of polypharmacy, PIM and PPO in patients aged 85 years and over has been described. In addition, regarding PIM, a higher prevalence when STOPP criteria were use in comparison to the Beers criteria, use of benzodiazepines as the primary cause for PIM, especially in people prone to falls, and a strong association with polypharmacy were found. Regarding PPO, omission of calcium plus vitamin D supplements in patients with osteoporosis as the primary cause for PPO, and a paucity of factors associated with PPO were reported on in this population. This multicentric study was carried out on a large cohort of the very elderly, an infrequently investigated group, and a comprehensive geriatric and pharmacological assessment of patients was applied. To improve the available information on the risk factors associated with PIM and especially with PPO, to analyze its consequences, to refine and adjust the PIM and PPO criteria, and finally, to carry out interventions to improve prescribing in this very elderly population, more research is needed.

\section{PIPOPS investigators}

Coordinator group: Antonio San-José (main investigator), Antònia Agustí, Xavier Vidal, Cristina Aguilera, Elena Ballarín, Eulàlia Pérez, Xavier Barroso.

Hospital Universitari Vall D’hebron (Barcelona): José Barbé, Carmen Pérez Bocanegra, Ainhoa Toscano, Carme Pal, Teresa Teixidor.

Hospital San Juan de Dios de Aljarafe (Sevilla): Antonio Fernández-Moyano, Mercedes Gómez Hernández, Rafael de la Rosa Morales, María Nicolás Benticuaga Martínez.

Hospital Clínic (Barcelona): Alfonso López-Soto, Xavier Bosch, $\mathrm{M}^{\mathrm{a}}$ José Palau, Joana Rovira, Margarita Navarro. 
Hospital Universitari de Bellvitge (Hospitalet de Llobregat, Barcelona): Francesc Formiga, David Chivite, Beatriz Rosón, Antonio Vallano, Carme Cabot.

Hospital Juan Ramón Jiménez (Huelva): Juana García, Isabel Ballesteros.

Hospital Santa Creu i Sant Pau (Barcelona): Olga H. Torres, Domingo Ruiz, Miquel Turbau, Paola Ponte, Gabriel Ortiz.

Hospital Universitario Virgen Del Rocío (Sevilla): Nieves Ramírez-Duque, Paula-Carlota Rivas Cobas, Paloma Gil.

\section{Additional file}

Additional file 1: Pharmacological anamnesis. (If used, cited authors as Fundació Institut Català de Farmacologia. Barcelona. Spain.

\section{Abbreviations}

ACE inhibitors: Angiotensin convertor enzyme inhibitors; ACOVE3: Assessing Care Of Vulnerable Elders 3; ADL: Activities of daily living; IP: Inappropriate prescription; PIM: Potentially inappropriate medicines; PPO: Potentially prescribing omissions; START: Screening tool to alert doctors to the right treatment; STOPP: Screening tool of older persons' potentially inappropriate prescriptions.

\section{Competing interests}

The authors declare that they have no competing interests.

\section{Authors' contributions}

ASJ, and AA, as directors and project leaders had devised and wrote the proposal for obtaining the grant, wrote the manuscript and had final responsibility for the decision to submit the manuscript for publication. ASJ, $A A, X V, F F, A L S, M G H, J G, N R D, O H T$, JB, contributed to the study design, coordinated data collection in each hospital, interpreted the data, reviewed the manuscript, provided comments and approved the final text of the manuscript. XV conducted statistical analysis. EB, and EP, controlled and monitorized quality data. $X B$ designed the database. $C A, C P, A T, C P, T T, D C h$, $B R, A V, C C, I B, D R, M T, P P, G O, P C R C, P G, A F M, R R M, M N B, X B, M J P, J R$ and MN collected the data.

\section{Acknowledgments}

The project was financed by Grant no. EC10-211 obtained in a request for aid for the promotion of independent clinical research (SAS/2370/2010 Order of 27 September from the Spanish Ministry of Health, Social Affairs and Equality).

\begin{abstract}
Author details
${ }^{1}$ Internal Medicine Service, Hospital Universitari Vall d'Hebron, Universitat Autònoma de Barcelona, Àrea General 3a planta, Passeig Vall d'Hebron 119-129, 08035 Barcelona, Spain. ${ }^{2}$ Clinical Pharmacology Service, Fundació Institut Català de Farmacologia, Hospital Universitari Vall d'Hebron, Departament of Pharmacology, Therapeutics and Toxicology, Universitat Autònoma de Barcelona, Barcelona, Spain. ${ }^{3}$ Internal Medicine Service, Hospital Universitari de Bellvitge. Hospitalet de Llobregat, Barcelona, Spain. ${ }^{4}$ Internal Medicine Service, Hospital San Juan De Dios del Aljarafe, Sevilla, Spain. ${ }^{5}$ Internal Medicine Service, Hospital General Juan Ramón Jiménez, Huelva, Spain. ${ }^{6}$ Internal Medicine Service, Hospital Clínic, Barcelona, Spain. ${ }^{7}$ Internal Medicine Service, Hospital Universitario Virgen del Rocío, Sevilla, Spain. ${ }^{8}$ Internal Medicine Service, Hospital Santa Creu i Sant Pau, Universitat Autònoma de Barcelona, Barcelona, Spain. ${ }^{9}$ Multimorbidity and elderly patients group of the Spanish Society of Internal Medicine, Barcelona, Spain.
\end{abstract}

Received: 22 December 2014 Accepted: 24 March 2015 Published online: 09 April 2015

\section{References}

1. Rechel B, Grundy E, Robine JM, Cylus J, Mackenbach JP, Knai C, et al. Ageing in the European Union. Lancet. 2013;381(9874):1312-22.
2. Barnett K, Mercer SW, Norbury M, Watt G, Wyke S, Guthrie B. Epidemiology of multimorbidity and implications for health care, research, and medical education: a cross-sectional study. Lancet. 2012;380(9836):37-43.

3. Formiga F, Ferrer A, Sanz H, Marengoni A, Alburquerque J, Pujol R, et al. Patterns of comobidity and multimorbidity in the oldest old: the Octabaix study. Eur J Intern Med. 2013;24(1):40-4.

4. Hughes LLD, McMurdo MET, Guthrie B. Guidelines for people not for disease: the challenges of applying UK clinical guidelines to people with multimorbidity. Age Ageing. 2013;42(1):62-9.

5. Strandberg TE, Kolehmainen L, Vuorio A. Evaluation and treatment of older patients with hypercholesterolemia: a clinical review. JAMA. 2014;312(11):1136-44.

6. Muller M, Smulders YM, de Leeuw PW, Stehouwer CD. Treatment of hypertension in the oldest old: a critical role for frailty? Hypertension. 2014;63(3):433-41.

7. Cruz-Jentoft AJ, Carpena-Ruiz M, Montero-Errasquín B, Sánchez-Castellano C, Sánchez-García E. Exclusion of older adults from ongoing clinical trials about type 2 diabetes mellitus. JAGS. 2013;61(5):734-8.

8. Cherubini A, Oristrell J, Pla X, Ruggiero C, Ferretti R, Diestre G, et al. The persistent exclusion of older patients from ongoing clinical trials regarding heart failure. Arch Intern Med. 2011;171(6):550-6.

9. Dalleur O, Spinewine A, Henrard S, Losseau C, Speybroeck N, Boland B. Inappropriate prescribing and related hospital admissions in frail older persons according to the STOPP and START criteria. Drugs Aging. 2012;29(10):829-37.

10. Spinewine A, Schmader KE, Barber N, Hughes C, Lapane KL, Swine C, et al. Appropriate prescribing in elderly people: how well can it be measured and optimised? Lancet. 2007;370(9582):173-84.

11. Cho S, Lau SW, Tandon V, Kumi K, Pfuma E, Abernethy DR. Geriatric drug evaluation: where are we now and where should we be in the future? Arch Intern Med. 2011;171(10):937-40.

12. Chang CB, Chan DC. Comparison of published explicit criteria for potentially inappropriate medications in older adults. Drug Aging. 2010;27(12):947-57.

13. Tsoi CS, Chow JY, Choi KS, Li HW, Nie JX, Tracy CS, et al. Medical characteristics of the oldest old: retrospective chart review of patients aged 85+ in an academic primary care centre. BMC Res Notes. 2014;7:340-7.

14. Wastesson JW, Parker MG, Fastbom JF, Thorslund M, Johnell K. Drug use in centenarians compared with nonagenarians and octagenarians in Sweden: a nationwide register-based study. Age Ageing. 2012;41:218-24.

15. San-José A, Agustí A, Vidal X, Formiga F, López-Soto A, Fernández-Moyano A, et al. Inappropiate prescribing to older patients admitted to hospital: a comparison of different tools of misprescribing and underprescribing. Eur J Intern Med. 2014;25(8):710-6.

16. San-José A, Agustí A, Vidal X, Barbé J, Torres OH, Ramírez-Duque N, et al. An interrater reliability study of the prescribing indicated medications quality indicators of the Assessing Care Of Vulnerable Elders (ACOVE) 3 criteria as a potentially inappropriate prescribing tool. Arch Gerontol Geriatr. 2014;58(3):460-4.

17. Fick DM, Cooper JW, Wade WE, Waller JL, Maclean JR, Beers MH. Updating the Beers criteria for potentially inappropriate medication use in older adults: results of a US consensus panel of experts. Arch Intern Med. 2003;163(3):2716-24

18. Gallagher PF, O'Mahony D. STOPP (screening tool of older persons' potentially inappropriate prescriptions): application to acutely ill elderly patients and comparison with Beers' criteria. Age Ageing. 2008;37(6):673-9.

19. Barry PJ, Gallagher P, Ryan C, O'Mahony D. START (screening tool to alert doctors to the right treatment)-an evidence-based screening tool to detect prescribing omissions in elderly patients. Age Ageing. 2007;36(6):632-8.

20. Ferrer A, Badia T, Formiga F, Sanz H, Megido MJ, Pujol R, et al. Frailty in the oldest old: prevalence and associated factors. JAGS. 2013;61(2):294-6.

21. Gallagher P, Lang PO, Cherubini A, Topinková E, Cruz-Jentoft A, Montero Errasquín B, et al. Prevalence of potentially inappropriate prescribing in an acutely ill population of older patients admitted to six European hospitals. Eur J Clin Pharmacol. 2011;67(11):1175-88.

22. Woolcott JC, Richardson KJ, Wiens MO, Patel B, Marin J, Khan KM, et al. Meta-analysis of the impact of 9 medication classes on falls in elderly persons. Arch Intern Med. 2009;169(21):1952-60.

23. Tannenbaum C, Martin P, Tamblyun R, Benedetti A, Ahmed S. Reduction of inappropriate benzodiazepine prescriptions among older adults through direct patient education. JAMA Intern Med. 2014;174(6):890-8.

24. van der Cammen TJ, Rajkumar C, Onder G, Sterke CS, Petrovic M. Drug cessation in complex older adults. Time for action. Age Ageing. 2014;43(1):20-5. 
25. Formiga F, Ferrer A, Almeda J, San Jose A, Gil A, Pujol R. Utility of geriatric assessment tools to identify 85 -years old subjects with vitamin $D$ deficiency. J Nutr Health Aging. 2011;15(2):110-4.

26. Hirani V, Cumming RG, Naganathan V, Blyth F, Le Couteur DG, Handelsman DJ, et al. Associations between serum 25-hydroxyvitamin D concentracions and multiple health conditions, physical performance measures, disability, and all cause mortality: the concord health and ageing in men project. J Am Geriatr Soc. 2014;62(3):417-25.

27. Andro M, Coutard A, Gentric A. Underuse in elderly adults: an underestimated suboptimal prescribing. J Am Geriatr Soc. 2012;68(8):1582-3.

28. Tang BM, Eslick GD, Nowson C, Smith C, Bensoussan A. Use of calcium or calcium in combination with vitamin D supplementation to prevent fractures and bone loss in people aged 50 years and older: a meta-analysis. Lancet. 2007;370(9844):657-66.

29. Bischoff-Ferrari HA, Willett WC, Wong JB, Stuck AE, Staehelin HB, Orav EJ, et al. Prevention of nonvertebral fractures with oral vitamin $D$ and dose dependency. Arch Intern Med. 2009;169(6):551-61.

30. Steinman MA, Landefeld CS, Rosenthal GE, Berthenthal D, Sen S, Kaboli PJ. Polypharmacy and prescribing quality in older people. J Am Geriatr Soc. 2006;54(10):1516-23.

31. Ryan C, O'Mahony D, Kennedy J, Weedle P, Cottrell E, Heffernan M, et al. Potentially inappropriate prescribing in older residents in Irish nursing homes. Age Ageing. 2012:42(1):116-20.

32. Frankenthal $D$, Lerman $Y$, Kalendaryev E, Lerman $Y$. Intervention with the Screening Tool of Older Persons Potentialy Inappropriate Prescriptions/ Screening Tool to Alert Doctors to Right Treatment Criteria in elderly residents of a chronic geriatric aacility: A randomized clinical trial. J Am Geriatr Soc. 2014;62(9):1658-65.

33. American Geriatrics Society 2012 Beers Criteria Update expert panel. American Geriatics Society updated Beers Criteria for potentially inappropriate medication use in older adults. J Am Geriatr Soc. 2012;60(4):616-31.

34. O'Mahony D, O'Sulivan D, Byrne S, O'Connor MN, Ryan C, Gallagher P. STOPP/START criteria for potentially inappropriate prescribing in older people: version 2. Age Ageing 2014. doi:10.1093/ageing/afu145.

\section{Submit your next manuscript to BioMed Central and take full advantage of:}

- Convenient online submission

- Thorough peer review

- No space constraints or color figure charges

- Immediate publication on acceptance

- Inclusion in PubMed, CAS, Scopus and Google Scholar

- Research which is freely available for redistribution 